\title{
A experiência do "Núcleo de Direitos das Pessoas com Deficiência" e os desafios para a efetividade da Convenção das Nações Unidas de 2007*
}

La experiencia del "Núcleo de derechos de las personas con deficiencia" y los desafíos para la efectividad de la convención de las Naciones Unidas de 2007

Psychometric properties of the attitudes questionnaire towards sexuality in old age (casv-10). Medellin- Colombia.

DOI: https://doi.org/10.21803/pensam.v11i21-1.260

Raquel Bellini de Oliveira Salles https://orcid.org/0000-0003-1329-9155

Aline Araújo Passos https://orcid.org/0000-0001-8620-4319

Nina Bara Zaghetto https://orcid.org/0000-0002-2505-3446

\section{¿Cómo citar este artículo?}

Bellini, R., Araújo, A. \& Bara, N. A experiência do "Núcleo de Direitos das Pessoas com Deficiência" e os desafios para a efetividade da Convenção das Nações Unidas de 2007. Pensamiento Americano, 11(21), 25- 39.

DOI: https://doi.org/10.21803/pensam.v17i21-1.260

\section{Resumo}

Com base na experiência do projeto de extensão e pesquisa intitulado "Núcleo de Direitos das Pessoas com Deficiência", em desenvolvimento na Universidade Federal de Juiz de Fora - Brasil, que tem por objetivos a identificação de violações de direitos e a prestação de assessoria jurídica gratuita a pessoas com deficiência de baixa renda, são compartilhadas algumas constatações no que diz respeito à (não) efetividade dos direitos fundamentais das pessoas com deficiência após a Convenção das Nações Unidas de 2007, sobretudo (i) a importância de se superar o modelo da prescindência e o modelo médico no tratamento das pessoas com deficiência, ainda arraigados socialmente, para se construir um concreto modelo social inclusivo; e (ii) a necessidade de enfrentamento de desafios considerados prementes, afetos à linguagem, à acessibilidade comunicacional, à educação e à empregabilidade. Demonstra-se que, apesar de decorridos mais de dez anos após a mencionada Convenção, o maior óbice para a construção de uma sociedade plenamente inclusiva ainda é a ausência de um real reconhecimento das pessoas com deficiência, o que requer qualificação e engajamento da sociedade. Apresentam-se, ainda, possibilidades e potencialidades do ensino, da pesquisa e da extensão no âmbito acadêmico para o fortalecimento de uma consciência geral mais sensível, atenta e proativa em favor das pessoas com deficiência.

Palavras-chave: pessoas com deficiência; direitos fundamentais; inclusão; reconhecimento.

\section{Resumo}

Com base na experiência do projeto de extensão e pesquisa intitulado "Núcleo de Direitos das Pessoas com Deficiência", em desenvolvimento na Universidade Federal de Juiz de Fora - Brasil, que tem por objetivos a identificação de violações de direitos e a prestação de assessoria jurídica gratuita a pessoas com deficiência de baixa renda, são compartilhadas algumas constatações no que diz respeito à (não) efetividade dos direitos fundamentais das pessoas com deficiência após a Convenção das Nações Unidas de 2007, sobretudo (i) a importância de se superar o modelo da prescindência e o modelo médico no tratamento das pessoas com deficiência, ainda arraigados socialmente, para se construir um concreto modelo social inclusivo; e (ii) a necessidade de enfrentamento de desafios considerados prementes, afetos à linguagem, à acessibilidade comunicacional, à educação e à empregabilidade.

Demonstra-se que, apesar de decorridos mais de dez anos após a mencionada Convenção, o maior óbice para a construção de uma sociedade plenamente inclusiva ainda é a ausência de um real reconhecimento das pessoas com deficiência, o que requer qualificação e engajamento da sociedade. Apresentam-se, ainda, possibilidades 
e potencialidades do ensino, da pesquisa e da extensão no âmbito acadêmico para o fortalecimento de uma consciência geral mais sensível, atenta e proativa em favor das pessoas com deficiência.

PALAVRAS-CHAVE: Pessoas com deficiência; direitos fundamentais; inclusão; reconhecimento.

\section{Resumen}

Basado en la experiencia del proyecto de extensión e investigación titulado "Núcleo de derechos de las personas con discapacidad", en desarrollo en la Universidad Federal de Juiz de Fora - Brasil, cuyos objetivos son la identificación de violaciones de derechos y la provisión de asesoramiento legal gratuito para las personas de bajos ingresos, algunos hallazgos se comparten con respecto a la (no) efectividad de los derechos fundamentales de las personas con discapacidad después de la Convención de las Naciones Unidas de 2007, en particular: (i) la importancia de superar el modelo de prescindencia y el modelo médico en el tratamiento de personas con discapacidades, todavía socialmente arraigadas, para construir un modelo social inclusivo concreto; y (ii) la necesidad de abordar los desafíos que se consideran apremiantes, en relación al idioma, a la accesibilidad comunicativa, a la educación y la empleabilidad. A pesar de que han transcurrido más de diez años desde la Convención, el mayor obstáculo para la construcción de una sociedad totalmente inclusiva es la falta de reconocimiento real de las personas con discapacidad, lo que requiere la calificación y el compromiso de la sociedad. Las posibilidades y potencialidades de la enseñanza, la investigación y la extensión en el campo académico también se presentan para fortalecer una conciencia general más sensible, atenta y proactiva a favor de las personas con discapacidad.

Keywords: Personas con deficiencia; derechos fundamentales, inclusión, reconocimiento

\section{Perfil}

Especialista em Direito Civil pela Università di Camerino - Itália. Advogada. Coordenadora do projeto de extensão e pesquisa universitária "Núcleo de Direitos das Pessoas com Deficiência". Professora de Direito Civil da Faculdade de Direito da Universidade Federal de Juiz de Fora (UFJF) - Brasil. E-mail: raquel.bellini@ufjf.edu.br.

\section{Perfil}

Advogada. Coordenadora do projeto de extensão e pesquisa universitária "Núcleo de Direitos das Pessoas com Deficiência". Professora de Direito Processual Civil e Diretora da Faculdade de Direito da Universidade Federal de Juiz de Fora (UFJF) - Brasil. E-mail: aline.passos@ufjf.edu.br.

\section{Perfil}

Estudante do curso de Direito da Universidade Federal de Juiz de Fora (UFJF) - Brasil. Bolsista do projeto de extensão e pesquisa universitária "Núcleo de Direitos das Pessoas com Deficiência". E-mail: NINA_BZ@hotmail.com.

\section{Raquel}

Bellini de Oliveira Salles

Mestre e Doutora em Direito Civil pela Universidade do Estado do Rio de Janeiro (UERJ).

\section{Aline \\ Araújo Passos}

Mestre e Doutora em Direito das Relacoes Sociais - Direito Processual Civil pela Pontificia Universidade Catolica de Sao Paulo (PUC-SP)

\section{Nina}

\section{Bara Zaghetto}

Estudiante de Derecho en la Universidad Federal de Juiz de Fora (UFJF) 


\section{Introducción}

$\mathrm{O}$ presente trabalho propõe uma análise da efetividade dos direitos fundamentais das pessoas com deficiência, com ênfase na experiência brasileira, após a Convenção Internacional de Nova Iorque assinada em $2007^{1}$ e a Lei Brasileira de Inclusão promulgada em 2015.² Tais atos normativos significaram uma mudança de paradigma quanto ao tratamento jurídico das pessoas com deficiência e instituíram uma perspectiva desestigmatizante e inclusiva que, contudo, ainda encontra muitos óbices e desafios para se concretizar.

O estudo visa compartilhar constatações havidas durante o desenvolvimento do projeto de extensão e pesquisa intitulado "Núcleo de Direitos das Pessoas com Deficiência", da Universidade Federal de Juiz de Fora - Brasil, que tem entre seus objetivos a identificação de violações dos direitos reconhecidos pela normativa antes mencionada e a prestação de assessoria jurídica gratuita a pessoas com deficiência de baixa renda. Com base na experiência do projeto, apresentam-se possibilidades e potencialidades do ensino, da pesquisa e da extensão no âmbito acadêmico para o fortalecimento de uma consciência geral mais sensível, atenta e proativa em favor das pessoas com deficiência.

Importa considerar que o intercâmbio de informações, vivências e soluções entre os países signatários da Convenção, entre eles o Brasil e a Colômbia ${ }^{3}$, muito pode contribuir para o impulso de reflexões transformadoras, para o redirecionamento de condutas da sociedade civil, das organizações e da administração pública e para o empreendi- mento de iniciativas voltadas à construção de um mundo verdadeiramente inclusivo.

O ponto de partida é o despertar para o imprescindível reconhecimento da pessoa com deficiência, para, então, serem enfrentados os desafios que se mostram mais urgentes para a sua real inclusão, sob uma ótica multi e interdisciplinar.

\section{O escopo do projeto "Núcleo de Direitos das Pessoas com Deficiência" e as poten- cialidades do ensino, da pesquisa e da ex- tensão na promoção da inclusão.}

O projeto em referência tem por objeto o estudo sobre os direitos das pessoas com deficiência e propõe-se a analisar a respectiva normativa internacional, constitucional e infraconstitucional, bem como a debater sua adequação, aplicação e efetividade na experiência brasileira. Além do aprofundamento de pesquisas, o "Núcleo de Direitos das Pessoas com Deficiência" oferece assessoria jurídica gratuita a pessoas de baixa renda.

A compreensão e enfrentamento jurídico dos problemas postos vêm sendo realizados com grupo selecionado de discentes paralelamente a visitas a institutos e organizações destinados a acolher as pessoas com deficiência e suas famílias, a fim de assegurar a construção cooperativa de um sistema de assessoramento jurídico em favor de tais pessoas. Busca-se o desempenho de ações extensionistas pautadas nos valores da universidade pública e na reciprocidade a ser estabelecida com a sociedade, com vistas à formação humanista dos alunos e à concretização dos direitos fundamentais das pessoas com deficiência.

\footnotetext{
Referida Convenção foi ratificada pelo Brasil em 2008 e entrou em vigor em agosto de 2009 por força do Decreto $n^{\circ} 6.949$ de 25 de agosto de 2009. 2 Lei $n^{\circ} 13.146$ de 6 de julho de 2015

3 Nesse sentido é que o Brasil firmou com a Colômbia, Chile e México, em 2017, termos de cooperação latino-americana, com foco na efetivação do artigo 32 da Convenção das Nações Unidas, que prevê a cooperação internacional entre os Estados, se necessário com apoio de organizações internacionais e regionais e da sociedade civil, para "facilitar e apoiar a capacitação, inclusive por meio do intercâmbio e compartilhamento de informações, experiências, programas de treinamento e melhores práticas".
} 
A justificativa para a concepção de tal projeto está na necessidade de proteção jurídica da pessoa com deficiência e de diálogos interdisciplinares, que invocam saberes da ciência do Direito, em suas variadas ramificações, e também de outras ciências. Importa considerar que o ordenamento brasileiro, assim como os sistemas jurídicos dos demais países signatários da Convenção de Nova lorque, sofreu profundas modificações dela decorrentes (Menezes, 2016). A subsequente Lei Brasileira de Inclusão, entre outras repercussões, deixou de identificar como civilmente incapaz a pessoa com deficiência e passou a prever o processo de tomada de decisão apoiada além da curatela, como expressão da tutela da dignidade-liberdade das pessoas com deficiência. A mudança de paradigma, que parte da premissa de que mesmo as pessoas com deficiência são plenamente capazes, salvo se houver necessidade de se reconhecer em juízo a incapacidade relativa para melhor tutelar os seus interesses, teve por escopo assegurar não só a dignidade da pessoa com deficiência, mas, sobretudo, sua plena inclusão social.

Para a realização de seu escopo, o projeto tem por metas: (i) identificar as transformações conceituais, estruturais e funcionais dos institutos jurídicos que tutelam a pessoa com deficiência, bem como compreender novos institutos, à luz da normativa internacional, constitucional e infraconstitucional; (ii) aprofundar pesquisas e realizar produções científicas voltadas à efetivação dos direitos das pessoas com deficiência, bem como acompanhar e analisar criticamente as orientações jurisprudenciais; (iii) fomentar nos alunos o interesse pela realização de atividades de apoio a pessoas com deficiência, contribuindo para o desenvolvimento de novos

extensionistas e atores sociais em tal área; (iv) estabelecer diálogo com as entidades de apoio e com as pessoas com deficiência, buscando diagnosticar suas principais demandas jurídicas e identificar os instrumentos mais adequados para a defesa de seus direitos; (v) produzir material informativo e realizar eventos para conscientização das próprias pessoas com deficiência, de suas famílias e da comunidade em geral acerca dos direitos de tais pessoas, buscando concretizá-los; (vi) prestar assessoria jurídica permanente e especializada; (vii) buscar a solução judicial ou extrajudicial de conflitos para a defesa dos direitos das pessoas com deficiência; (viii) acompanhar processos legislativos sobre o tema e atuar em audiências públicas, no intuito de promover discussões para a efetivação dos direitos fundamentais das pessoas com deficiência. Metodologicamente, as atividades de extensão são divididas em três eixos, considerando os seguintes segmentos: (i) interação com instituições que auxiliam e promovem a inclusão das pessoas com deficiência; (ii) interação com órgãos públicos que atuam na assistência e defesa dos direitos das pessoas com deficiência; e (iii) interação com pessoas com deficiência e suas famílias, especialmente as de baixa renda.

A partir da ampla investigação que vem sendo realizada, mostra-se possível assegurar a construção de trabalho coletivo e participativo, que envolva todos os atores que atuam na defesa das pessoas com deficiência, de forma a permitir maior visibilidade às questões dessas pessoas e a assegurar a ampliação do exercício de sua cidadania e a inclusão social.

Explicitadas as linhas gerais do projeto em referência, passa-se a demonstrar as principais percepções havidas até o momento a partir de experiências concretas, destacando-se a necessidade de superação de antigos modelos de tratamento jurídico das 
pessoas com deficiência, ainda arraigados socialmente, bem como os desafios cujo enfrentamento mostra-se mais urgente para a efetivação dos direitos fundamentais de tais pessoas.

\section{A superação de antigos modelos e o ne- cessário reconhecimento da pessoa com deficiência.}

O tratamento da deficiência como questão de direitos humanos foi tardio (Barboza \& Almeida, 2017, p.6) e se deu com a Convenção das Nações Unidas de 2007, como resultado de um processo de elaboração que contou com a participação ativa e inédita da sociedade civil (Dhanda, 2007), incluindo organizações não governamentais e pessoas com deficiência. Todavia, a enunciação normativa de direitos não significa necessariamente a inexistência de obstáculos à sua efetivação.

A Convenção, seguida pela Lei Brasileira de Inclusão, trouxe inegavelmente uma mudança de orientação no modelo de tratamento da pessoa com deficiência, que passa a ser um modelo social, a ensejar o redimensionamento de tal pessoa nas diversas áreas da vida. Vale lembrar que, antes disso, haviam sido concebidos outros modelos, que, atualmente, ao menos em tese, podem-se dizer superados: o modelo da prescindência e o modelo médico.

Segundo o modelo da prescindência, as causas originárias das deficiências tinham um fundamento religioso, sendo entendidas como mensagens "diabólicas", e pessoas com deficiência e suas vidas eram consideradas "inúteis". A sociedade, portanto, "prescindiria" dessas pessoas (Madruga, 2016, p.34). Já o modelo médico decorre dos padrões científicos da modernidade e encara a deficiência como condição patológica, de natureza individual. Desse modo, a pessoa deveria ser tratada com intervenções médicas, deveria ser "reparada", para tornar-se, o quanto possível, "normal". Esse modelo tem como características principais a substituição da divindade pela ciência e a admissão da possibilidade de algum aporte para a sociedade por parte das pessoas com deficiência, na medida em que sejam "reabilitadas" ou "normalizadas" (Barboza e Almeida, 2017, p. 14). Não obstante os grandes avanços do modelo médico quanto ao reconhecimento de garantias específicas em relação às pessoas com deficiência, este as considerava inadequadas à convivência social, por deterem um atributo individual oriundo de suas patologias, propugnando que fossem ocultadas até o indivíduo ser reabilitado, preparado, para enfrentar de igual para igual os demais membros da coletividade (sem deficiência). O problema, assim, estaria "no indivíduo", na sua anormalidade (Madruga, 2016, p. 36).

Diversamente, no modelo social, a deficiência é um problema geral que exige intervenções na sociedade e pela sociedade; as causas da deficiência não são religiosas, nem somente médicas; são predominantemente sociais. As raízes dos problemas não são as restrições ou diferenças individuais, mas as limitações ou impedimentos impostos pela sociedade, que não tem meios, serviços ou instrumentos adequados para realizar a inclusão (Barboza \& Almeida, 2017, p.17). Noutros termos, o problema está "na sociedade" e, não, no indivíduo. A valoração do indivíduo como pessoa e a necessidade de sua inclusão aproximam o modelo social de premissas dos direitos humanos, máxime do princípio da dignidade, ao considerar, em primeiro plano, o respeito à pessoa, seguido, quando necessário, de circunstâncias particulares específicas, relacionadas propriamente à deficiência, entre elas 
a história clínica da pessoa (Madruga, 2016 p. 36). A propósito, Barboza e Almeida (2017) afirmam:

O primeiro, se não o mais importante, efeito da adoção do modelo social consiste em promover a inversão da perspectiva na apreciação da deficiência, que deixa de ser uma questão unilateral, do indivíduo, para ser pensada, desenvolvida e trabalhada como relação bilateral, na qual a sociedade torna-se efetivamente protagonista, com deveres jurídicos a cumprir (p.17).

Depreende-se, portanto, que o desafio na tutela integral das pessoas com deficiência reside na ineficácia social das normas que decorre em boa medida de sua invisibilidade e não reconhecimento, eis que desde a década de 1980 já existe legislação específica, mas a situação pouco avançou na defesa dos direitos desse grupo vulnerável (p. 23).

A ausência de reconhecimento revela-se, pois, o maior óbice à efetivação dos direitos fundamentais das pessoas com deficiência e do pretendido modelo social, ameaçando a eficácia não apenas das normas internacionais, mas também das normas constitucionais e de seus regulamentos legais. Sobre o que se entende por reconhecimento, Honneth (2009) enfatiza as ideias de que "os sujeitos humanos devem sua identidade à experiência de um reconhecimento intersubjetivo" (p.125), de modo que "um sujeito só pode adquirir uma consciência de si mesmo na medida em que ele aprende a perceber sua própria ação da perspectiva, simbolicamente representada, de uma segunda pessoa" (p.131). Para o citado filósofo, "um sujeito é capaz de se considerar, na experiência do reconhecimento jurídico, como uma pessoa que partilha com todos os outros membros de sua coletividade as propriedades que ca- pacitam para a participação numa formação discursiva da vontade" (p.197), e a "solidariedade" pode ser entendida, numa primeira aproximação, como "uma espécie de relação interativa em que os sujeitos tomam interesses reciprocamente por seus modos distintos de vida, já que eles se estimam entre si de maneira simétrica" (p. 209), ou seja, de maneira que "todo sujeito recebe a chance, sem graduações coletivas, de experienciar a si mesmo, em suas próprias realizações e capacidades, como valioso para a sociedade" (p.211).

O reconhecimento é, assim, a ponte necessária para que seja possível, mais do integrar, incluir as pessoas com deficiência. A inclusão, diversamente da mera integração, embora com esta não seja incompatível, chama a sociedade à ação, por exigir que se adapte para acolher tais pessoas (Barboza e Almeida, 2017, p.11). A integração, na realidade, já era buscada antes mesmo da Convenção de 2007, o que pode ser exemplificado por diversas normas constantes da Constituição da República Federativa do Brasil, de 1988, de natureza mais assistencialista, tais como as que determinam a reserva de percentual de cargos e empregos públicos, a adoção de requisitos e critérios diferenciados para a concessão de aposentadoria, a prestação de assistência social com os objetivos de habilitação, reabilitação e promoção de integração à vida comunitária, a garantia de um salário mínimo de benefício mensal se comprovada a impossibilidade de prover a própria manutenção ou de tê-la provida pela família, o atendimento educacional especializado, o acesso adequado a logradouros e edifícios de uso público e a veículos de transporte coletivo. Como afirmam Barboza e Almeida (2017),

Através da integração buscava-se o fim da prática de exclusão social que atingiu durante séculos a pessoa com deficiên- 
cia. A exclusão significava o banimento total dessas pessoas de qualquer atividade social, por serem consideradas inválidas, incapazes de trabalhar, portanto sem utilidade para a sociedade. O processo de integração objetivava incorporar física e socialmente as pessoas com deficiência e oferecer-lhes os instrumentos existentes para o exercício da cidadania. Sem embargo desse objetivo, o qual tinha sem dúvida propósitos bem intencionados, verifica-se que a integração dependia da capacidade de adaptar-se ao meio, de superar as barreiras físicas, programáticas e atitudinais presentes na sociedade que permanecia inerte. Nesta perspectiva, as pessoas com deficiência seriam especiais e deveriam se "normalizar" o quanto possível, vale dizer, se adaptar à "normalidade" (p.10).

Para além da integração, mostra-se crucial promover a inclusão, refirmando-se e fortalecendo-se a autonomia das pessoas com deficiência, para o que os esforços não devem ser apenas delas, mas de toda a sociedade. Isso requer, a partir do reconhecimento, também qualificação e engajamento de todos os envolvidos.

A qualificação da sociedade deve ocorrer, primeiramente, no plano da linguagem, mediante a superação de terminologias imprecisas, preconceituosas ou discriminatórias, que se valem, por exemplo, de expressões como "deficientes" (pois a pessoa não é deficiente, ela tem deficiência), "portadores de deficiência" (pois a pessoa não porta a deficiência como algo anexo) ou "pessoas especiais ou excepcionais". Além disso, é necessário superar os preconceitos oriundos da falta de conhecimento sobre as causas das deficiências, em sua multiplicidade, complexidade e particularidades, o que carece de informação. A qualificação social requer um processo de assimilação cultural da coexistência e da convivência entre diferenças, o que a educação, em todas as fases de formação, deve zelar para que aconteça, contribuindo para uma conscientização mais enraizada sobre como se comunicar, como tratar e como se relacionar com as pessoas com deficiência, além de viabilizar vínculos e trocas. A capacitação da sociedade também requer a preparação dos profissionais, em todas as áreas, carreiras e níveis, para o acolhimento de tais pessoas, o que pode se realizar mediante a inserção nos currículos dos cursos técnicos e superiores, inclusive de maneira transdisciplinar, de temáticas afetas às pessoas com deficiência, às suas especificidades, aos seus direitos.

O engajamento social, por seu turno, deve repercutir iniciativas privadas e públicas atentas às necessidades de tais pessoas como usuárias de serviços, consumidoras, contratantes, contribuintes e aos seus interesses existenciais e patrimoniais afetos à saúde, à educação, à moradia, ao trabalho, à locomoção, à informação, à cultura e ao lazer, propiciando-lhes condições suficientes de acessibilidade, de comunicação e de independência tanto quanto possível. Faz-se inarredável "a implementação de políticas públicas, programas sociais e serviços adaptados que permitam a superação de barreiras" (Barboza e Almeida, p. 25), o que não é sustentável sem planejamento de curto, médio e longo prazos, sem metas e sem discussões orçamentárias que coloquem em pauta os direitos das pessoas com deficiência, de modo a evitar a frequente alegação de "reserva do possível" devido à escassez de recursos financeiros.

A invisibilidade e a indiferença, depreendidas da realidade que nos cerca e perceptível pela experiência mais comum, refletem a falta daquele necessário reconhecimen- 
to da pessoa com deficiência e, por conseguinte, da ausência de efetividade das normas jurídicas já concebidas. Por isso, o maior problema que se coloca não é tanto a inércia do legislativo e nem encontra sua solução definitiva no judiciário. $\bigcirc$ modelo social precisa concretizar-se além das letras da lei, reverberar na cultura e nas rotinas até que se possa naturalizar nas mais diversas dimensões das relações intersubjetivas e sociais.

\section{Desafios prementes para a efetivação dos direitos das pessoas com deficiência: linguagem, acessibilidade comunicacio- nal, educação e empregabilidade.}

A efetivação dos direitos fundamentais das pessoas com deficiência invoca a necessidade de enfrentamento de problemas em várias áreas, oriundos justamente da falta do mencionado reconhecimento da pessoa com deficiência, a começar pela linguagem e pela comunicação.

Como explicita Silva (2017), na relação com o desconhecido, com o diferente, é possível situar a relação dialógica e de alteridade na interação entre o eu e o outro como sujeitos. Bakhtin (como citado em Silva, 2017) propõe o estudo da ideologia em que a linguagem, os signos e/ou a palavra são carregados de conteúdo ideológico imerso no processo de interação entre os sujeitos, sendo o elo de uma corrente ininterrupta de pensamento. $O$ autor examina a relação do eu-para-mim (como me percebo, minha consciência) com indagações de como este eu se forma e se percebe a partir das relações com o outro. No caso das pessoas surdas, como ainda demonstra Silva (2017, p.114), é possível analisar qual concepção o surdo tem de si mesmo a partir de seu olhar como "ser surdo", sua diferença linguística em relação às pessoas ouvintes. Nesse sen- tido, "ser surdo" e ter consciência disso na sociedade ouvinte é algo que ainda está em construção.

Observa-se que, num primeiro momento, o surdo ainda não se reconhece como tal, pois sua noção de surdez surge a partir do contato com outro ouvinte ou com outro surdo, sendo que, comumente, na escola regular, o aluno surdo tem seu primeiro contato com alunos ouvintes e com o professor ouvinte (Silva, 2017, p.115). Suas referências linguística e visual são constituídas a partir de uma vivência que não atende às peculiaridades de ser surdo. Em um universo regulado pelo falar e pelo ouvir, se todos ouvem, supõe-se que o surdo também deve ouvir; se todos copiam, o surdo também deve copiar, "copiar" o outro, ser como o outro, ser para o outro, ser o outro. O outro é quem dá ao aluno surdo toda a visão de quem é e de quem não é. Ademais, nenhuma pessoa é igual à outra, nenhum surdo é igual ao outro e a própria concepção de ser surdo depende das relações que este tem com os outros surdos ou com os ouvintes. Entretanto, para muitos ouvintes, o "ser surdo" ainda está atrelado à ideia de incapaz, uma visão que limita o espaço social das pessoas surdas nas escolas, no ambiente de trabalho e até mesmo na família (Silva, 2017, p.114). Essa fronteira entre surdos e ouvintes, em suas relações entre o eu e o outro, geralmente não leva em consideração que os surdos e os ouvintes podem se constituir mutuamente nas relações sociais por meio da língua, da cultura e da relação de alteridade (Silva, 2017, p.121-122).

Justamente atentando-se para essas possibilidades, o processo de constituição de cada um pode ser enriquecido significativamente com a experiência do outro, permitindo o desenvolvimento de habilidades linguísticas, comunicacionais e relacionais, 
a ruptura de preconceitos, o crescimento de todos na compreensão e na vivência das diferenças, a relação de alteridade como vetor de uma formação humanista, a convivência em lugar da segregação.

Esse entendimento foi incorporado à Convenção das Nações Unidas de 2007 e à Lei Brasileira de Inclusão, que determinam a superação da ideia de que somente a educação especial, organizada de forma paralela à educação comum, seria a mais apropriada para os alunos com deficiência, passando à compreensão de que a educação especial deve integrar a proposta pedagógica da escola regular. Como afirma Konder (2017):

O atendimento educacional especializado, com organização de recursos pedagógicos e de acessibilidade que eliminem as barreiras para a plena participação dos alunos, considerando suas necessidades específicas, deixa de ser substitutivo daquele realizado na sala de aula comum, assumindo um papel complementar da formação dos alunos, com vistas à autonomia e independência na escola e fora dela. Em termos práticos, pode demandar, de forma articulada com a proposta pedagógica do ensino comum, a disponibilização de programas de enriquecimento curricular, o ensino de linguagens e códigos específicos de comunicação e sinalização e tecnologia assistiva (p.37).

E tal é um direito ao qual corresponde um dever jurídico. Nesse sentido, o Supremo Tribunal Federal julgou improcedente a Ação Direta de Inconstitucionalidade (ADIN) $n^{\circ}$ 5.357-MC ${ }^{4}$, que questionava uma série de medidas determinadas pela Lei Brasileira de Inclusão voltadas a assegurar um sistema educacional inclusivo, com os custos inerentes, tanto nas redes públicas quanto privadas. A questão, além de invocar a educação inclusiva como parte do mínimo existencial da pessoa e a eficácia horizontal (nas relações privadas) dos direitos fundamentais (Konder, 2017), foi enfrentada com ênfase no fundamento de que a inclusão é medida necessária não apenas para os alunos com deficiência, mas, também, para os alunos sem deficiência, como sintetizou o Ministro Relator Luiz Edson Fachin, nos seguintes trechos de seu voto:

(...) A atuação do Estado na inclusão das pessoas com deficiência, quer mediante o seu braço Executivo ou Legislativo, pressupõe a maturação do entendimento de que se trata de ação positiva em uma dupla via.

Explico: essa atuação não apenas diz respeito à inclusão das pessoas com deficiência, mas também, em perspectiva inversa, refere-se ao direito de todos os demais cidadãos ao acesso a uma arena democrática plural. A pluralidade - de pessoas, credos, ideologias, etc. - é elemento essencial da democracia e da vida democrática em comunidade. (...)

Assim, a igualdade não se esgota com a previsão normativa de acesso igualitário a bens jurídicos, mas engloba também a previsão normativa de medidas que efetivamente possibilitem tal acesso e sua efetivação concreta. (...)

Nessa mesma linha, em sede doutrinária se percebeu que "(...) conviver com a diferença não é direito dos diferentes apenas; é direito nosso, da maioria, de poder conviver com a minoria; e aprender a desenvolver tolerância e acolhimento". (Brasil, Supremo Tribunal Federal, Ação

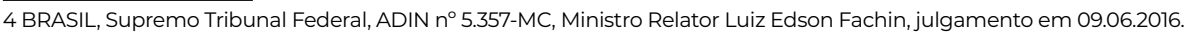


Direta de Inconstitucionalidade $n^{\circ} 5.357-$ MC, 2016)

Tal premissa é importante não apenas no âmbito da educação, pois, qualquer que seja a relação estabelecida com uma pessoa com deficiência, a convivência dialógica implica no processo de formação da identidade de todos os envolvidos, já que a relação intersubjetiva reverbera tanto na pessoa com deficiência quanto na pessoa sem deficiência, permitindo que a construção da imagem do outro impacte na própria concepção de si.

Ainda no tocante à comunicação, cabe enfrentar outro desafio, que é o conhecimento e a implementação da audiodescrição (AD) como ferramenta inclusiva voltada à pessoa com deficiência visual, a qual faz a descrição das imagens em palavras. Scoralick (2016) explica que "além da TV, a AD pode ser usada também no teatro, museu, cinema, palestras, espetáculos de dança, musicais e outras situações que requerem a descrição de um elemento visual não compreendido ou percebido por causa de uma deficiência visual" (p.2) vel às pessoas "com deficiência intelectual, com dislexia, idosos, pessoas com déficit de atenção, autistas e outros", inclusive o público infantil (p.10).

Por meio da audiodescrição, promove-se a acessibilidade comunicacional, superando-se barreiras na comunicação interpessoal, escrita e virtual, alusiva à acessibilidade digital. No entanto, sobre a ausência do uso de tal recurso especialmente no telejornalismo, Scoralick (2016) alerta para as particularidades das pessoas com deficiência visual:
Percebe-se, assim, que para assistir TV e às notícias nos telejornais o sentido da visão é preponderante. Temos que as imagens falam por si só, traduzem posturas, condições. Significam. E ganham eficácia ainda maior quando complementam ou são complementadas por um texto. Mas e quando o público é formado por pessoas com deficiência visual ou baixa visão? Como essas imagens são percebidas ou podem chegar até eles? "Para Valvo, um oftalmologista, as pessoas cegas constroem o mundo a partir de sequências de impressões táteis, auditivas e olfativas, já que, por não serem capazes da percepção visual simultânea, não concebem uma cena visual instantânea" (LIMA, 2006, p. 83). A visão para os cegos é um sentido complementar, e não dominante. As imagens mentais são construídas a partir de um sistema perceptivo organizado de modo diferente (p. 7).

Fazendo referência ao acesso à cultura, a autora citada (Scoralick, 2017) também atenta para o tímido e lento uso da audiodescrição, seja porque, de um lado, "o público com deficiência, por muito tempo à margem da produção cultural em todos os ambientes, ainda não tem o hábito de frequentar esses espaços ou acompanhar a programação de tais meios de comunicação", seja porque, de outro lado, o produtor cultural "diz não ter interesse em produzir trabalhos acessíveis, como audiodescrição, por exemplo, porque não tem público. E assim mantém-se esse ciclo vicioso" (p.15). Nesse ponto, a vulnerabilidade da pessoa com deficiência e o imperativo de inclusão impõem aos produtores culturais e organizadores de eventos de qualquer natureza um protagonismo na ruptura de dito círculo vicioso, de modo que

5 A autora relata que "No Brasil, a regulamentação do recurso de audiodescrição só foi realizada para o meio televisivo. O uso de AD neste veículo acontece desde julho de 2011 , seguindo determinação da Portaria $n^{\circ} 188$, de 25 de março de 2010 . As emissoras de TV estão obrigadas a cumprir, no mínimo, seis horas semanais com o recurso. E deve atingir 20 horas semanais em um prazo de 10 anos, a contar da data da publicação da portaria. No entanto, o recurso de AD na televisão aparece predominantemente em filmes e seriados. E em alguns programas ao vivo, híbridos, não puramente jornalísticos, é realizado de forma esporádica. Ainda não se tem conhecimento do seu uso em telejornalismo, nem mesmo em outros países" (Scoralick, 2016, p. 2). 
devem diligenciar meios para tornar não apenas acessíveis, mas também atrativas às pessoas com deficiência as atividades e serviços que venham a oferecer.

É interesse notar, ainda no âmbito da acessibilidade comunicacional, que também em eventos, inclusive de natureza acadêmica, o apontado reconhecimento da pessoa com deficiência pode se realizar tanto com a atuação de intérpretes de línguas de sinais e de audiodescritores, quanto com o engajamento dos próprios expositores, já que, para uma qualificada interpretação de sinais e audiodescrição, os respectivos profissionais necessitam ter disponibilizados, com antecedência razoável, os textos, apresentações e imagens que subsidiarão as falas. Trata-se, contudo, de prática ainda não naturalizada, mas que depende apenas de conscientização e planejamento, enfim, de mudanças de rotinas cuja realização cabe precipuamente à sociedade.

Também nas relações de trabalho igualmente se clama por reconhecimento, qualificação e engajamento em favor das pessoas com deficiência, não obstante seja amplo no Brasil o arcabouço normativo que protege tais pessoas nesse âmbito. Com efeito, a Convenção das Nações Unidas de 2007 trouxe o princípio da não discriminação, em convergência com o que já dispunha a Constituição brasileira ao proibir, no artigo $7^{\circ}, X X X I$, qualquer ato discriminatório quanto à remuneração e critérios de admissão do trabalhador. O artigo 37, VIII, também do texto constitucional, determina a reserva de percentual dos cargos e empregos públicos para as pessoas com deficiência. A Lei Brasileira de Inclusão igualmente estabelece diretrizes para a garantia de condições satisfatórias de trabalho para a pessoa com deficiência e veda qualquer discriminação em razão de sua condição, inclusive nas eta- pas de recrutamento, seleção, contratação, admissão, exames admissional e periódico, permanência no emprego, ascensão profissional e reabilitação profissional, bem como a exigência de aptidão plena. Estabelece o direito à participação e o acesso a cursos, treinamentos, educação continuada, planos de carreira, promoções, bonificações e incentivos profissionais oferecidos pelo empregador, em igualdade de oportunidade com os demais empregados, garantida a acessibilidade em cursos de formação e de capacitação. Ainda segundo a referida lei, os programas de estímulo ao empreendedorismo e ao trabalho autônomo, incluídos o cooperativismo e o associativismo, devem prever a participação da pessoa com deficiência e a disponibilização de linhas de crédito, quando necessárias, sendo que é finalidade primordial das políticas públicas de trabalho e emprego promover e garantir condições de acesso e de permanência da pessoa com deficiência no campo de trabalho. Enfim, de conformidade com a lei mencionada, constitui modo de inclusão da pessoa com deficiência no trabalho a colocação competitiva, em igualdade de oportunidade com as demais pessoas, atendendo-se às regras de acessibilidade, o fornecimento de recursos de tecnologia assistiva e a adaptação razoável do ambiente de trabalho. Importante mencionar, também, o disposto no artigo $428, \S 5^{\circ}$, da Consolidação das Leis do Trabalho brasileira, segundo o qual a idade máxima de 24 anos para o termo final do contrato de aprendizagem não se aplica à pessoa com deficiência, consideradas suas particularidades, pois ainda é preciso vencer uma prática contumaz que é a falta de permanência na escola regular para a conclusão do ensino obrigatório e ascensão para outras etapas de formação (Gugel, 2016, p.428).

Apesar de se mostrar bem amplo e avança- 
do o sistema protetivo da pessoa com deficiência no campo do trabalho, sua concretização ainda não é uma plena realidade no Brasil, o que se deve a diversos fatores.

Observa Madruga (2016), que "às pessoas com deficiência são reservadas as taxas de pobreza mais elevadas, piores níveis de saúde e escolaridade e menor participação econômica, em decorrência, principalmente, das barreiras de acesso aos serviços que se entendem básicos: saúde, educação, emprego, transporte e informação" (p. 31). Segundo o autor, a interface negativa entre deficiência, de um lado, e pobreza, de outro, conduz à marginalização e à vulnerabilidade e, por conseguinte, à exclusão dessas pessoas, sendo que a deficiência tanto pode ser causa quanto advir da pobreza, situação agravada nos países menos desenvolvidos:

Está-se diante de um verdadeiro círculo vicioso e que precisa ser rompido. A desnutrição infantil, por exemplo, pode ter como consequência uma deficiência, que, por sua vez, se apresenta como obstáculo ao acesso à educação, que gera falta de formação escolar e redunda, mais adiante, em escassez ou falta de emprego. Este último fator causa mais pobreza para pessoa com deficiência e seus familiares, o que Ihes impossibilita o acesso à alimentação, saúde e moradia adequadas, e a partir daí o círculo recomeça (Madruga, 2016, p. 33).

Pode-se dizer que a ínfima participação das pessoas com deficiência no mercado de trabalho e na geração de riquezas para o país não decorre da falta de um sistema protetor, mas da falta de estímulo e incentivo de instituições que viabilizem a inserção dessas pessoas, oferecendo-Ihes as oportunidades necessárias, para que demonstrem o seu potencial. Pastore (2000) preleciona que tal ínfima participação.

decorre não da falta de leis e de fiscalização, mas sim da carência de ações, estímulos e instituições que viabilizem, de forma concreta, a formação, habilitação, reabilitação e inserção dos portadores de deficiência no mercado de trabalho (p. 59).

Nos países mais desenvolvidos que adotam o sistema de cotas, este é apenas uma peça no complexo enredo de leis, programas, instituições e incentivos econômicos concebidos para favorecer o trabalho das pessoas com deficiência. Bertolin (2012) afirma que:

há de se observar que, geralmente, os países que se preocupam com a qualidade de vida de seus deficientes são aqueles que passaram por longas guerras e viram retornar um grande número de mutilados, que tinham por obrigação receber bem. O Brasil não teve essa experiência e, portanto, não conseguiu esse amadurecimento. Muito ao contrário, em nosso país, grande número de deficiências é causado - ou agravado - pela miséria, que cria gerações de subnutridos, e pela inexistência de um serviço de saúde, que garanta a todos um pré-natal, por meio do qual muitas doenças poderiam ser evitadas ou tratadas; miséria que induz as pessoas a prestarem trabalho submetidas às piores condições, com grave risco à sua saúde e à sua integridade física. Considere-se, ainda, que tais pessoas, doentes ou acidentadas, não recebem tratamento ou reabilitação, que Ihes permita retornar às suas atividades [...] Leis, há muitas, sobre o assunto. Belas leis em consonância com os mais modernos documentos internacionais acerca da matéria. 'Mas o maior desafio é o da mudança cultural, 
e esta não se realiza por decreto'. Urge uma reforma cultural, pois um país que não trata seus cidadãos como seres humanos e não lhes garante, de fato, os direitos mais fundamentais (e o trabalho é condição para a inserção do ser humano na sociedade; e condição para a cidadania) está fadado a nunca sair da miséria.

Nota-se significativa mudança de pensamento em vários países, principalmente do continente europeu, com uma tendência clara rumo ao que se chama de "rede de apoio", tripé baseado em leis antidiscriminação, sistemas de cotas e esquemas de contribuição e terceirização. Pode-se entender que a rede de apoio é uma articulação de instituições formais e não-formais que atuam no sentido de educar, formar, reabilitar, informar, intermediar e criar estímulos para inserir, reter e recolocar os portadores de deficiência no mercado de trabalho da maneira menos traumática possível e, uma vez dentro dele, assisti-los com amparo técnico, psicológico, econômico e social (Pastore, 2000, p.180). A finalidade das redes de apoio é garantir às pessoas com deficiência a oportunidade de viver de modo mais próximo possível ao das demais pessoas, o que envolve reabilitação médica, educação, treinamento, equipamentos, habilidades profissionais, serviços especializados, disposição de empregar, tolerância no ambiente de trabalho, entre outras atitudes.

Diante desse cenário, revela-se essencial a promoção de condições de empregabilidade das pessoas com deficiência não apenas mediante oferta de postos de trabalho, mas, também, de meios de desenvolvimento, aprendizado e crescimento no cotidiano das empresas e das organizações, de modo a viabilizar a permanência na vaga ofertada. $\bigcirc$ foco de atenção deve dirigir-se além da reserva de vagas para alcançar também a sua qualidade, de modo a possibilitar o desempenho de funções não meramente operacionais, níveis hierárquicos superiores e remunerações compatíveis com a qualificação dos trabalhadores. Para tanto, as pessoas com deficiência devem ter oportunidades efetivas de capacitação para atingirem melhor empregabilidade, o que passa por sua formação escolar, técnica, superior e profissionalizante e, também, pela preparação e conscientização dos colegas de trabalho, em todos os níveis. É fato que, sem adequada qualificação e engajamento de todos, a inclusão de profissionais com deficiência no mercado de trabalho torna-se ainda mais difícil.

\section{Conclusão}

Com base na experiência do projeto de extensão e pesquisa intitulado "Núcleo de Direitos das Pessoas com Deficiência", em desenvolvimento na Universidade Federal de Juiz de Fora - Brasil, foram compartilhadas algumas constatações, especialmente (i) a importância de se superar o modelo da prescindência e o modelo médico no tratamento das pessoas com deficiência, ainda arraigados socialmente, para se construir um concreto modelo social inclusivo; e (ii) a urgência de enfrentamento de desafios afetos à linguagem, à acessibilidade comunicacional, à educação e à empregabilidade.

É indubitável que, a partir da Convenção das Nações Unidas de 2007, as pessoas com deficiência tornaram-se mais visíveis juridicamente. Todavia, decorridos mais de dez anos após a mencionada Convenção, ainda não é possível dizer que vivemos numa sociedade plenamente inclusiva. O maior óbice, como visto, é a ausência de um real reconhecimento dessas pessoas, bem como de qualificação e engajamento de todos os envolvidos.

Em termos de resultados parciais, pode-se 
dizer que o projeto mencionado vem promovendo uma maior aproximação entre a instituição de ensino - universidade - e a sociedade, com vistas a permitir que o trabalho de pesquisa jurídica acerca das pessoas com deficiência possa não só repercutir na formação dos alunos e alunas, mas também assegurar a ampliação da defesa dos direitos daquelas pessoas a partir do diagnóstico de suas necessidades e da percepção sobre os inúmeros desafios para o seu reconhecimento.

Os impactos na formação discente vêm se mostrando muito positivos, haja vista a oportunidade de aprofundamento nas temáticas de direitos humanos e de conhecimento da legislação e da fundamentação teórica para a proteção das pessoas com deficiência. A pesquisa associada à extensão vem permitindo que os envolvidos no projeto vivenciem a diversidade e, assim, tenham condições de contribuir, na sua vida profissional, como verdadeiros atores da construção de uma sociedade mais solidária e substancialmente igualitária. As atividades extensionistas de atendimento ao público e de visitas às entidades de apoio às pessoas com deficiência viabilizam a compreensão da realidade e das dificuldades enfrentadas diariamente. Além disso, o conhecimento das políticas públicas levanta reflexões sobre possíveis mecanismos de enfrentamento coletivo dos problemas que obstaculizam a efetivação dos direitos das minorias.

A execução do projeto evidencia, enfim, a indissociabilidade entre ensino, pesquisa e extensão, pois permite, mediante contato direto com a comunidade, a assunção da extensão como uma das dimensões da vida acadêmica, oportunizando aos discentes a vivência do processo ensino-aprendizagem além da sala de aula, com a possibilidade de articularem a universidade diretamente à sociedade, numa enriquecedora troca de conhecimentos e experiências, sempre com o objetivo de fortalecer a cidadania das pessoas envolvidas. A pesquisa, por seu turno, é pressuposta e contínua para a execução do projeto em todas as suas fases, pois a tutela jurídica da pessoa com deficiência demanda conhecimento de diversos ramos do Direito e de outros campos do saber, desenvolvendo habilidades analíticas, críticas e de decisão, para a identificação da solução jurídica mais adequada para cada problema concreto, o correto manejo de variados instrumentos jurídicos, extrajudiciais e judiciais, os posicionamentos doutrinários e jurisprudenciais aplicáveis, os custos envolvidos e, ainda, a viabilidade de novos mecanismos concebidos ou que venham a surgir.

O empreendimento de projetos dessa natureza é mecanismo de promoção do reconhecimento das pessoas com deficiência, reafirmando a função promocional do Direito, segundo Bobbio (2007), para a construção de uma sociedade efetivamente inclusiva. 


\section{Referencias}

Barboza, H. \& Almeida Junior, V. (2017). Reconhecimento, inclusão e autonomia da pessoa com deficiência: novos rumos na proteção dos vulneráveis. En: Barboza, H. H.; Mendonça, B. L. \& Almeida Junior, V. de A. (Coord), O Código Civil e o Estatuto da Pessoa com Deficiência (pp. 1-30). Rio de Janeiro, Brasil: Editora Processo.

Bertolin, P. T. M. (2012). A discriminação às pessoas com deficiência nas relações de trabalho. Revista dos Tribunais Online, disponivel em: http://www. rtonline.com.br/.

Bobbio, N. (2007). Dalla struttura alla funzione. Roma, Italia: Editori Laterza.

Dhanda, A. (2007). Legal capacity in the disability rights convention: stranglehold of the past or lodestar for the future? Syracuse Journal of International Law and Commerce. 34(2), pp. 429-462.

Gugel, M. A. (2012). O direito ao trabalho e ao emprego: a proteção na legislação trabalhista. En: FERRAZ, C. V. et al., Manual dos direitos da pessoa com deficiência (pp.412-431). São Paulo, Brasil: Saraiva.

Honneth, A. (2009). Luta por reconhecimento: a gramática moral dos conflitos sociais. São Paulo, Brasil: Editora 34.

Madruga, S. (2016). Pessoas com deficiência e direitos humanos: ótica da diferença e ações afirmativas. São Paulo, Brasil: Saraiva.

Menezes, J. (2016). Direito das pessoas com deficiência psíquica e intelectual nas relações privadas. Rio de Janeiro, Brasil: Editora Processo.

Pastore, J. (2000). Oportunidades de trabalho para portadores de deficiência. São Paulo, Brasil: LTr.

Scoralick, K. (2017). Por uma TV acessivel: a audiodescrição e as pessoas com deficiência visual (Tesis Doctoral). Universidade Federal do Rio de Janeiro, Rio de Janeiro.

Scoralick, K. (2016). Telejornalismo e acessibilidade comunicacional: um olhar para o outro com deficiência. En: $14^{\circ}$ Encontro Nacional de Pesquisadores em Jornalismo - SBPJOR. Palhoça, Brasil: SBPJor - Associação Brasileira de Pesquisadores em Jornalismo.

Silva, C. V. (2017). O processo de interação entre os sujeitos surdos e os sujeitos ouvintes a partir de Bakhtin. En: FREITAS, M. T. de A.; RAMOS, B. S. da S., Bakhtin Partilhado (pp. 109-124). Curitiba, Brasil: CRV. 